\title{
Transcriptome analysis in petals and leaves of chrysanthemums with different chlorophyll levels
}

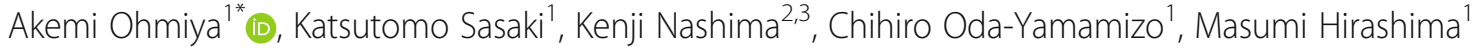 \\ and Katsuhiko Sumitomo ${ }^{1}$
}

\begin{abstract}
Background: Chlorophylls (Chls) are magnesium-containing tetrapyrrole macromolecules responsible for the green color in plants. The Chl metabolic pathway has been intensively studied and nearly all the enzymes involved in the pathway have been identified and characterized. Synthesis and activity of these enzymes are tightly regulated in tissue- and developmental stage-specific manners. Leaves contain substantial amounts of Chls because Chls are indispensable for photosynthesis. In contrast, petals generally contain only trace amounts of Chls, which if present would mask the bright petal color. Limited information is available about the mechanisms that control such tissue-specific accumulation of Chls.

Results: To identify the regulatory steps that control Chl accumulation, we compared gene expression in petals and leaves of chrysanthemum cultivars with different Chl levels. Microarray and quantitative real-time PCR analyses showed that the expression levels of $\mathrm{Chl}$ biosynthesis genes encoding glutamyl-tRNA reductase, Mg-protoporphyrin IX chelatase, Mg-protoporphyrin IX monomethylester cyclase, and protochlorophyllide oxidoreductase were well associated with $\mathrm{Chl}$ content: their expression levels were lower in white petals than in green petals, and were highest in leaves. Among Chl catabolic genes, expression of STAY-GREEN, encoding Mg-dechelatase, which is a key enzyme controlling Chl degradation, was considerably higher in white and green petals than in leaves. We searched for transcription factor genes whose expression was well related to Chl level in petals and leaves and found three such genes encoding MYB113, CONSTANS-like 16, and DREB and EAR motif protein.
\end{abstract}

Conclusions: From our transcriptome analysis, we assume that a low rate of $\mathrm{Chl}$ biosynthesis and a high rate of Chl degradation lead to the absence of Chls in white chrysanthemum petals. We identified several candidate transcription factors that might affect $\mathrm{Chl}$ accumulation in chrysanthemum petals. Functional analysis of these transcription factors will provide a basis for future molecular studies of tissue-specific Chl accumulation.

Keywords: Chlorophyll metabolism, Chrysanthemum (Chrysanthemum morifolium Ramat.), Gene expression, Petal color, Transcription factor

\section{Background}

Chlorophylls (Chls) are magnesium-containing tetrapyrrole macromolecules responsible for the green color in plants. Because Chls play a central role in light harvesting and energy transduction in photosynthesis, mature leaves contain a substantial amount of Chls [1]. Petals of many flowering plants contain Chls at early developmental

\footnotetext{
* Correspondence: ohmiya@affrc.go.jp

${ }^{1}$ Institute of Vegetable and Floriculture Science, National Agriculture and Food Research Organization, Fujimoto 2-1, Tsukuba, Ibaraki 305-0852, Japan

Full list of author information is available at the end of the article
}

stages [2]. As petals develop, Chl content decreases, and petals of fully opened flowers contain only trace amounts of Chls. The absence of Chls in petals is an important trait that enables flowers to be visually distinguished by pollinators against a background of leaves when the flowers are ready to be pollinated.

The Chl metabolic pathway can be divided into three distinct phases (Fig. 1) [3-5]: (1) biosynthesis of Chl a from glutamate; (2) interconversion between $\mathrm{Chl} a$ and $b$ (Chl cycle); and (3) degradation of Chl $a$ into a nonfluorescent Chl catabolite. Nearly all enzymes involved 


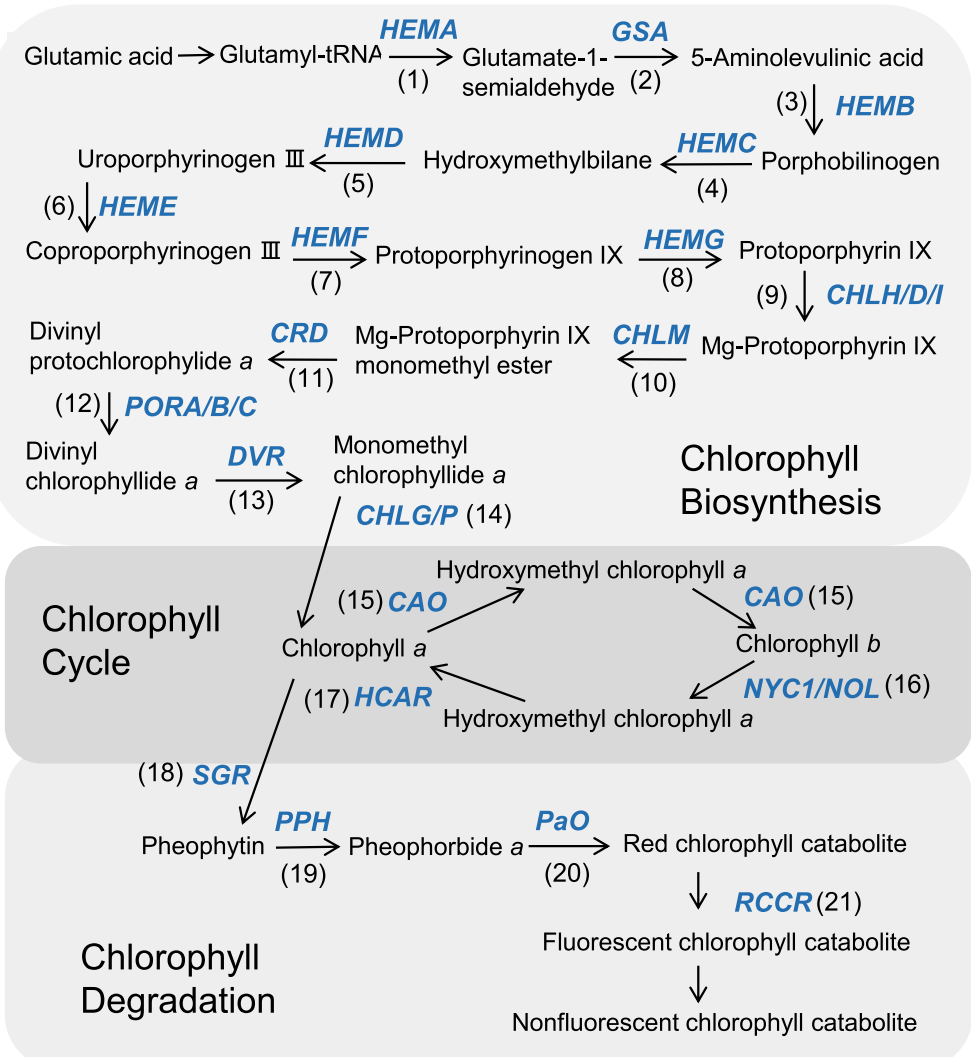

Fig. 1 Schematic representation of Chl metabolic pathways in higher plants. Genes (italicized) encode the following enzymes: (1) glutamyl-tRNA reductase; (2) glutamate-1-semialdehyde 2,1-aminotransferase; (3) 5-aminolevulinate dehydrogenase; (4) porphobilinogen deaminase; (5) uroporphyrinogen III synthase; (6) uroporphyrinogen III decarboxylase; (7) coproporphyrinogen III oxidase; (8) protoporphyrinogen oxidase; (9) Mg-chelatase; (10) Mg-protoporphyrin IX methyltransferase; (11) Mg-protoporphyrin IX monomethylester cyclase; (12) protochlorophyllide oxidoreductase; (13) divinyl chlorophyllide a 8-vinyl-reductase; (14) Chl synthase; (15) chlorophyllide a oxygenase; (16) Chl b reductase; (17) hydroxymethyl Chl a reductase; (18) STAY-GREEN (Mg-dechelatase); (19) pheophytinase; (20) pheophorbide $a$ oxygenase; (21) red Chl catabolite reductase

in the pathway are identified and characterized. In higher plants, synthesis and activity of these enzymes are tightly regulated in tissue- and developmental stage-specific manners.

There is increasing evidence that the Chl biosynthesis pathway is transcriptionally regulated in a tissue-specific manner $[4,6]$. Several transcription factors have been identified as negative or positive regulators of the Chl biosynthesis pathway. GOLDEN2-LIKE (GLK), LONG H YPOCOTYL5 (HY5), and GATA, NITRATE-INDUCIBLE, CARBON-METABOLISM INVOLVED (GNC) regulate Chl biosynthesis in leaves [7-9], whereas GNC-LIKE (GNL)/CYTOKININ RESPONSIVE GATA FACTOR1 (CGA1) enhances Chl biosynthesis in petals and stamens [9]. PHYTOCHROME-INTERACTING FACTOR 1 (PIF1) and PIF3 inhibit the biosynthesis of protochlorophyllide by interacting with photoreceptors in leaves in the dark [10]. Chl degradation is also regulated at the transcriptional level. Recently, ORE1 and ANAC046 have been shown to increase the expression of Chl catabolic genes [11, 12]. Changes in the expression of genes for these transcription factors influence Chl content in Arabidopsis leaves, but limited information is available about the regulation of $\mathrm{Chl}$ metabolism in non-photosynthetic tissues.

As mentioned above, it is a distinct disadvantage for insect-pollinated flowers to accumulate Chls in petals. Therefore, even if a mutation that results in green flowers occurs, such plants may be eliminated from their natural habitat. In contrast, in ornamental plant breeding, greenflowered mutants are preferably selected and developed as cultivars. In this study, we used white- and green-flowered cultivars of chrysanthemum (Chrysanthemum morifolium Ramat.) to investigate the mechanisms that regulate $\mathrm{Chl}$ content in petals. We compared the expression profiles of genes related to $\mathrm{Chl}$ metabolism between these cultivars and searched for genes whose expression levels are positively or negatively associated with Chl content. We also searched for genes encoding transcription factors whose expression is regulated in coordination with Chl content in petals. From these data, we identified candidate transcription factors controlling Chl accumulation in chrysanthemum petals. 


\section{Methods}

\section{Plant materials}

The chrysanthemum (Chrysanthemum morifolium Ramat.) cultivars Feeling White (FW), Feeling Green (FG), and Feeling Green Dark (FGD) (Japan Agribio Co., Shizuoka, Japan) were grown under natural daylight in a greenhouse at our institute (Tsukuba, Ibaraki, Japan). FGD and FW were bud sports arising from FG. Other white- and greenflowered chrysanthemum cultivars were purchased from the local market in Tsukuba. Petals of ray florets and the 3 rd visible leaves from the top were harvested, immediately frozen in liquid nitrogen, and stored at $-80{ }^{\circ} \mathrm{C}$ until use.

\section{Microarray analysis}

We previously constructed a chrysanthemum expressed sequence tag (EST) database with 213,204 contigs [13]. Short contigs ( $<100 \mathrm{bp})$ and no-hit contigs (<197 bp) were omitted, and 176,026 contigs were chosen for custom oligonucleotide array design. Oligonucleotides of about 60 bases representing each EST were designed by Takara Bio (Ohtsu, Shiga, Japan) as described by Ohba et al. [14]. Oligonucleotides were synthesized on a glass surface $(4 \times 180 \mathrm{k})$ with SurePrint technology (Agilent Technologies, Palo Alto, CA, USA).

For microarray analysis, we chose petals at $\mathrm{S} 2$ because the difference in chlorophyll content among FW, FG, and FGD became evident at this stage. Total RNA was extracted from ray floret petals of FW, FG, and FGD at S2, and mature leaves of FG using Trizol reagent (Thermo Fisher Scientific, Waltham, MA, USA) and an RNeasy Mini Kit (Qiagen, Hilden, Germany). RNA integrity was evaluated using an Agilent 2100 Bioanalyzer (Agilent Technologies). Total RNA samples (100 ng) were used as starting materials. Three biological replicates were examined by the one-color method according to Nashima et al. [15]. Spot signal values were calculated with Agilent Feature Extraction version 9.1 software. Hierarchical clustering using Pearson correlation was performed with the tree-clustering tool of the Subio platform (Subio Inc., Kagoshima, Japan). The datasets for hierarchical clustering were normalized using a low signal cutoff (mean raw signal <100), $\log _{2}$-transformation, global normalization, and centering.

Gene ontology (GO) categorization was performed according to the to the annotation of the Arabidopsis gene corresponding to each probe [13]. GO terms were obtained from The Arabidopsis Information Resource (TAIR, http://www.arabidopsis.org/) (ATH GO GOSLIM , updated 2013 May 15).

\section{Quantitative real-time PCR analysis}

Quantitative real-time PCR (RT-qPCR) was performed as described previously [16]. cDNA for each gene was amplified by RT-PCR, cloned into the pGEM-T Easy Vector (Promega, Madison, WI, USA), and sequenced. Primers for RT-qPCR were designed from the sequences (Additional file 1 Table S1). Each plasmid was serially diluted 10-fold and used for a standard curve assay. The transcript copy number was determined by relating the RT-qPCR signal for each gene to a standard curve. The mRNA levels were calculated relative to that of actin (IABW01167629), which was constitutively expressed in leaves and petals as indicated by our microarray data. Analysis was performed in biological triplicate, and statistical significance was analyzed by Tukey-Kramer multiple-comparison test $(P<0.05)$.

\section{Chlorophyll analysis}

Tissues were ground into powder in liquid nitrogen and extracted with acetone. The samples were centrifuged at $10,000 \times g$ for $10 \mathrm{~min}$, and the supernatants $(80 \mu \mathrm{l})$ were mixed with $20 \mu \mathrm{l}$ of water. Pigments were analyzed by high-performance liquid chromatography (HPLC; X-LC, Jasco, Tokyo, Japan) using a reversed-phase column (Symmetry C8, $150 \times 4.6 \mathrm{~mm}$; Waters, Milford, MA, USA) according to Zapata et al. [17]. The analysis was performed in biological triplicate.

\section{Transmission electron microscopy}

Tissues were cut into small pieces (approximately $1 \mathrm{~mm}^{3}$ ), fixed, dehydrated, and embedded in Quetol 651 (Nisshin EM Co., Tokyo, Japan) as described previously [12]. Ultrathin sections were cut with a diamond knife on an ultramicrotome (Ultracut UCT, Leica Microsystems, Wetzlar, Germany). Sections were picked up on copper grids, stained with uranyl acetate and lead citrate, and observed under a transmission electron microscope (TEM) (JEM1200EX; JEOL Ltd., Tokyo, Japan) at an acceleration voltage of $80 \mathrm{kV}$. Digital images were taken with a CCD camera (Veleta; Olympus Soft Imaging Solutions $\mathrm{GmbH}$, Münster, Germany).

\section{Results}

\section{Chlorophyll content in petals and leaves}

To identify genes coordinately expressed with Chl content, we used ray floret petals and leaves containing different Chl levels. In the white-flowered cultivar FW, small amounts of Chls accumulated in petals at the early developmental stage (S1) (Fig. 2). At the late stage (S3), Chl content decreased to extremely low levels. Larger quantities of Chls were detected in petals of the greenflowered cultivars FG and FGD than in those of FW especially at S3 (Additional file 4 Figure S2). At S3, FGD petals contained more Chls than FG and FW petals. At this stage, Chl content in FG leaves was 12.85 times that in FG petals and 6.56 times that in FGD petals. Because 

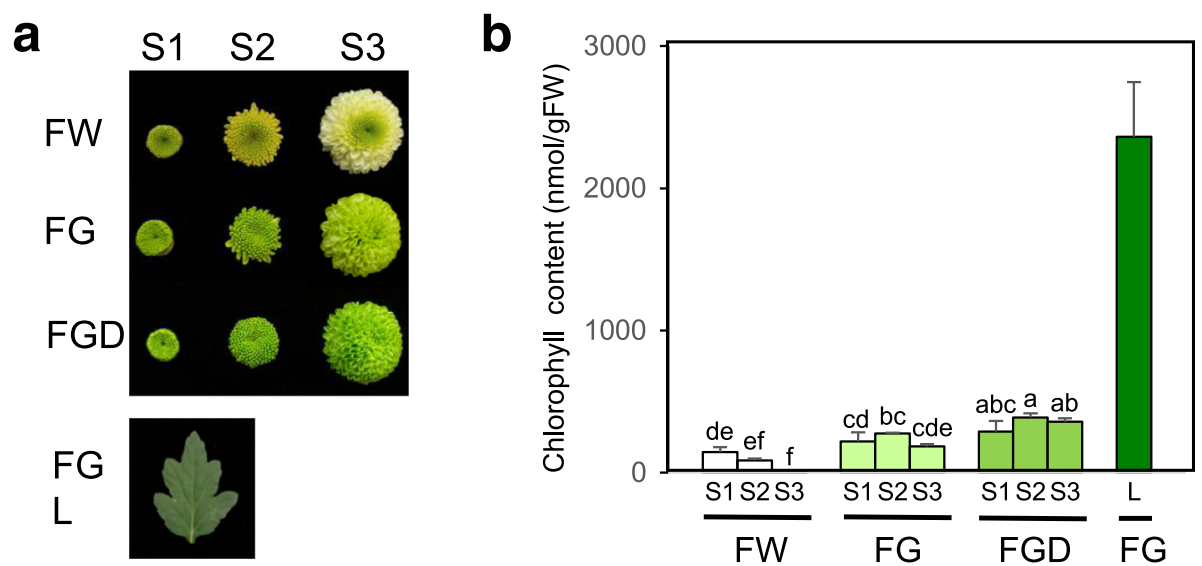

Fig. 2 Chl content in petals and leaves of chrysanthemums. a Photographs of flowers of FW (Feeling White), FG (Feeling Green), and FGD (Feeling Green Dark) and an FG leaf (L). Flower development was divided into three stages: S1, 2-3 days after calyx opening; S2, ray florets at the outermost part of the capitulum begin to open; and S3, approximately $90 \%$ of ray florets are open. $\mathbf{b}$ Chl content in petals at different developmental stages and in mature leaves. Mean values ( \pm SD) of three biological replicates are shown. The differences among petals (FW, FG, and FGD) were analyzed by Tukey-Kramer multiple-comparison test. Different letters indicate significant differences at $P<0.05$

there was no significant difference in leaf Chl content among FW, FG, and FGD (Additional file 2 Figure S1), leaves of FG were used for further study.

\section{Gene ontology classification of differentially expressed genes} Using microarray data, we extracted genes with the expression levels in FW or FGD petals $>5$ times greater or lower than in FG petals and examined the distribution of gene ontology terms (Fig. 3). In the cellular component category, genes associated with "plastid", "chloroplast", "other cytoplasmic component", "other intracellular component", and "other membrane" were highly enriched among the downregulated genes in FW petals. In the biological process category, genes associated with "electron transport or energy pathways", which include photosynthesis-related genes, were also highly represented among the downregulated genes in FW petals. No marked differences were found in the molecular function category.

\section{Microarray and RT-qPCR analyses of chlorophyll-related gene expression}

The chrysanthemum custom oligonucleotide array constructed in this study covered most genes involved in Chl metabolism (Additional file 3 Table S2). Microarray analysis was performed using this array and the expression profiles of selected genes of interest were further analyzed using RT-qPCR for a wider range of developmental stages of each tissue.

\section{Chl biosynthesis}

Many of the genes involved in Chl biosynthesis showed higher expression in FG and FGD petals than in FW petals (Fig. 4a). In particular, genes in group 1, CHLH (encoding
Mg-protoporphyrin IX chelatase [Mg-chelatase] H subunit), $C R D$ (encoding Mg-protoporphyrin IX monomethylester cyclase), HEMA1 (encoding glutamyl-tRNA reductase), and PORC (encoding protochlorophyllide oxidoreductase $\mathrm{C}$ ) showed significantly higher expression in FG and FGD petals than in FW petals; the highest expression of these genes was found in FG leaves $(P<0.01)$. There were no significant differences in the expression levels of $H E M D$ (encoding uroporphyrinogen III synthase), CHLG (encoding Chl synthase), CHLM (encoding Mg-protoporphyrin IX methyltransferase), HEMG2 (encoding protoporphyrinogen III oxidase), or CHLI (encoding Mg-chelatase I subunit).

Because the expression patterns of group 1 genes were positively matched with Chl content, we hypothesized that these genes play an important role in determining Chl content in petals and further analyzed their expression by RT-qPCR. As in microarray analysis, the levels of CHLH, CRD, HEMA1, and PORC transcripts were highest in leaves and were extremely low in FW petals (Fig. 5). In FGD, the expression of all four genes tended to increase as petals matured.

\section{Chl cycle}

Among genes related to the $\mathrm{Chl}$ cycle, the expression of two group 2 genes, NOL (Non-yellow coloring onelike, encoding Chl $b$ reductase subunit) and HCAR (encoding hydroxymethyl $\mathrm{Chl} a$ reductase), was well correlated with Chl content: it was lower in FW petals than in FG and FGD petals and was remarkably high in FG leaves (Fig. 4b). RT-qPCR analysis of $N O L$ and HCAR showed similar expression patterns to those observed in the microarray analysis (Fig. 5). In FG and FGD, the expression of group 2 genes tended to increase as petals matured. 


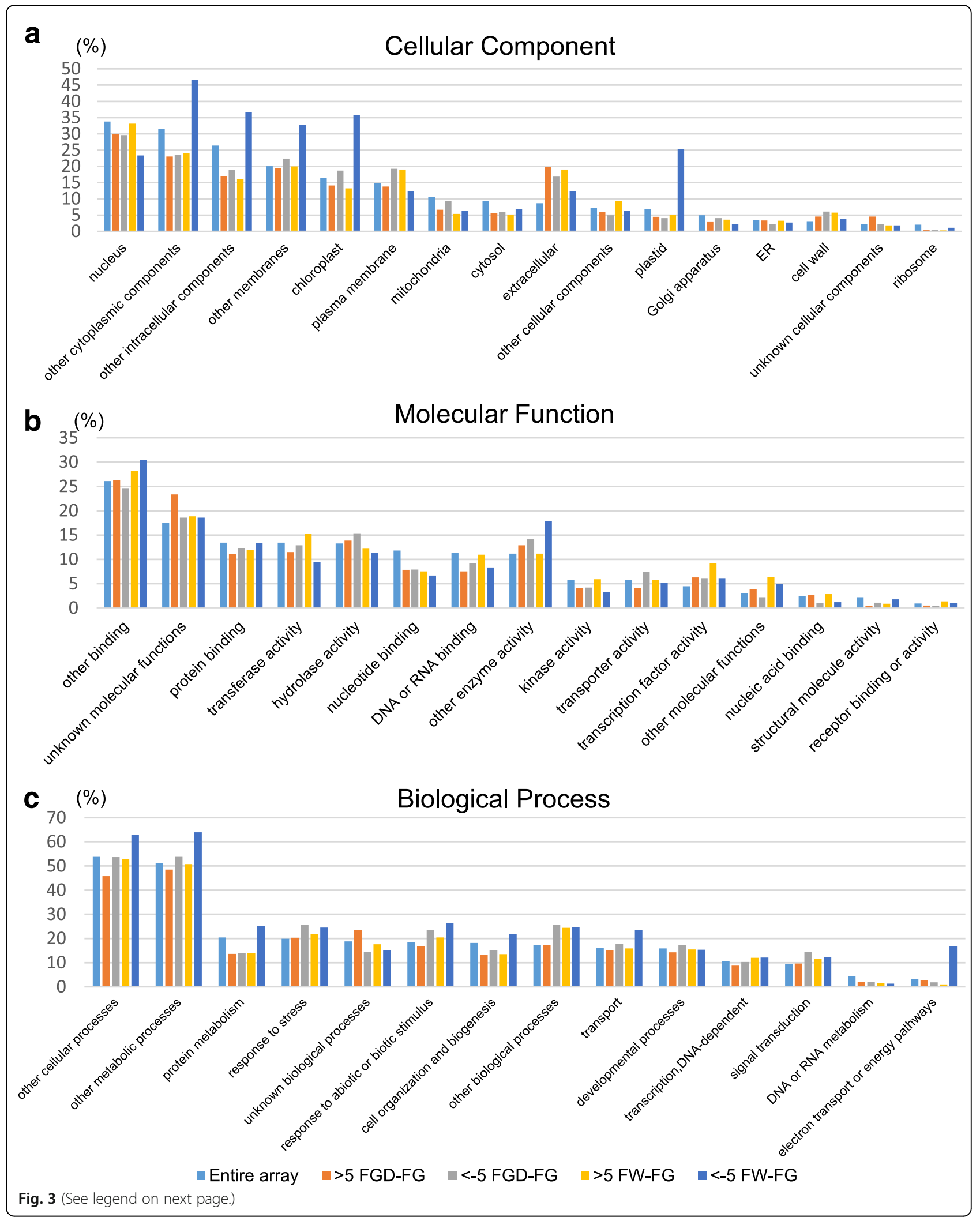


(See figure on previous page.)

Fig. 3 Gene ontology classification of genes differentially expressed in FW, FG, and FGD petals. Expression of genes in stage 2 petals was compared between FW and FG and between FGD and FG. Genes were classified into categories (cellular component, molecular function, and biological process) after being mapped to the Gene Ontology database. The $y$-axis indicates the percentage of genes in each functional category, calculated from the number of genes whose expression in FW or FGD petals was $>5$ times greater or lower than that in FG petals

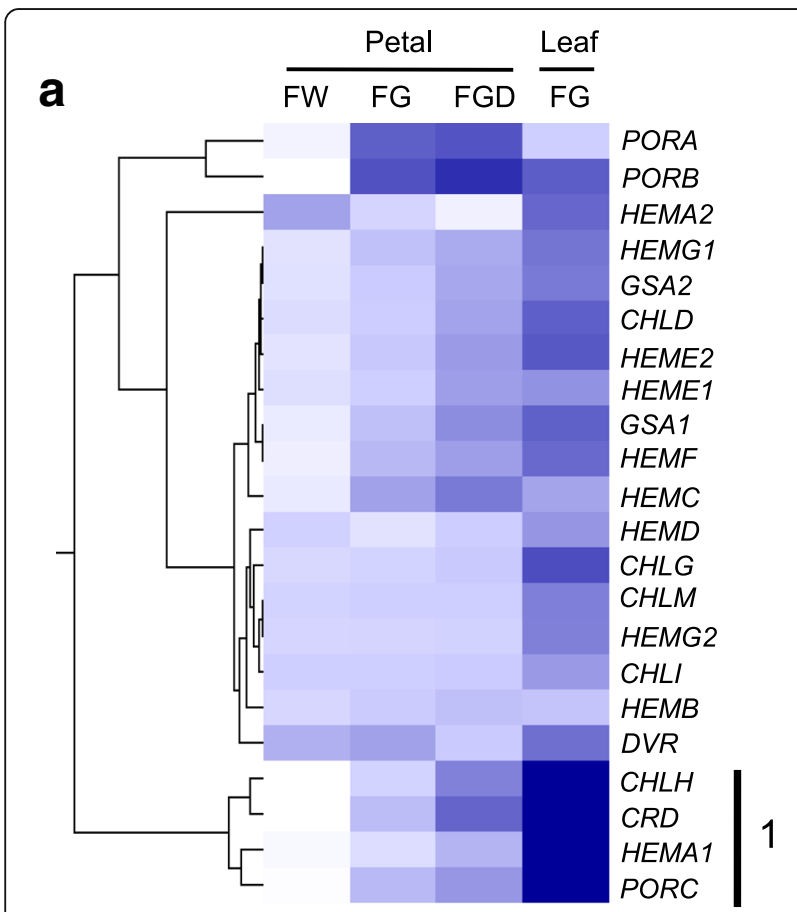

b

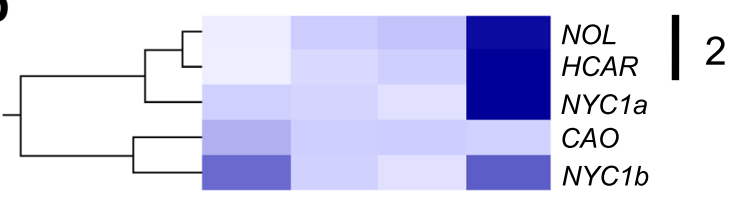

C

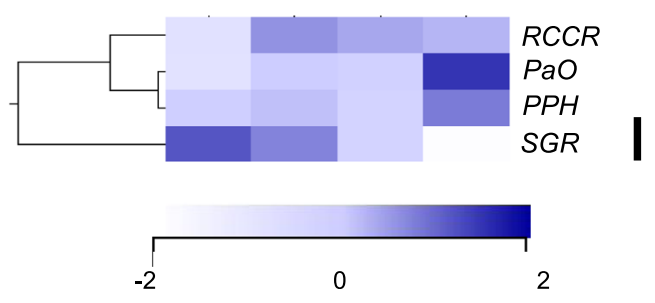

Fig. 4 Overview of expression profiles of genes related to (a) $\mathrm{Chl}$ biosynthesis, (b) Chl cycle, and (c) Chl degradation in petals and leaves of chrysanthemum. The microarray data was obtained from S2 petals of FW, FG, and FGD and from mature leaves of FG. The data was clustered with respect to the transcript profiles of genes, and dendrograms are shown on the left of the heat map. Data represent $\log _{2}$-normalized signal values of transcript levels, which are continuously mapped on the color scale provided at the bottom of the figure

\section{Chl degradation}

Among genes related to Chl degradation, the expression of only SGR (STAY-GREEN, encoding Mg-dechelatase) showed negative correlation with Chl content, with the highest expression in FW petals and extremely low in leaves (Fig. 4c). There was no clear relationship between $\mathrm{Chl}$ content and expression levels of $R C C R$ (encoding red $\mathrm{Chl}$ catabolite reductase), $\mathrm{PaO}$ (encoding pheophorbide $a$ oxygenase), and $P P H$ (encoding pheophytinase). RT-qPCR analysis showed that the expression levels of $S G R$ drastically increased as petals matured in FW, FG, and FGD, whereas that in leaves was very low (Fig. 5). Because an oligo probe specific to the SGR-like gene, a homologue of SGR, was absent from our custom oligonucleotide array, SGR-likespecific primers were designed based on its chrysanthemum EST sequence, and RT-qPCR was performed. Unlike $S G R$ expression, that of SGR-like was lower in petals than in leaves during the course of development.

\section{Comparison of gene expression between green and white petals}

To confirm our findings, we compared the expression of group 1 and 2 genes and SGR (Fig. 4) in S3 petals of several white- and green-flowered cultivars (Additional file 4 Figure S2). Chl content in S3 petals was $<1.4 \mathrm{nmol} / \mathrm{g}$ fresh weight ( $g$ FW) in white-flowered cultivars and 147$424 \mathrm{nmol} / \mathrm{g} \mathrm{FW}$ in green-flowered cultivars (Fig. 6a). Among group 1 genes (CRD, CHLH, HEMA1, and PORC), only the expression of $C R D$ was significantly higher in green petals than in white petals in all cultivars tested (Fig. 6b). Expression of the other three genes tended to be higher in green petals than in white petals in most cultivars compared. There was a considerable variability among cultivars in the expression levels of group 2 genes (NOL and HCAR) and SGR, with no significant correlation between transcript levels and Chl content.

\section{Transcription factors differentially expressed in FW and FGD petals in comparison with FG petals}

To identify transcription factors involved in the regulation of Chl accumulation in petals, we analyzed transcription factor genes whose expression was positively or negatively related to Chl content. Tables 1 and 2 list transcription factor genes differentially expressed between FG and FW petals and between FG and FGD petals, respectively, in our microarray data $(P<0.01$ and fold change $> \pm 15$ ). 

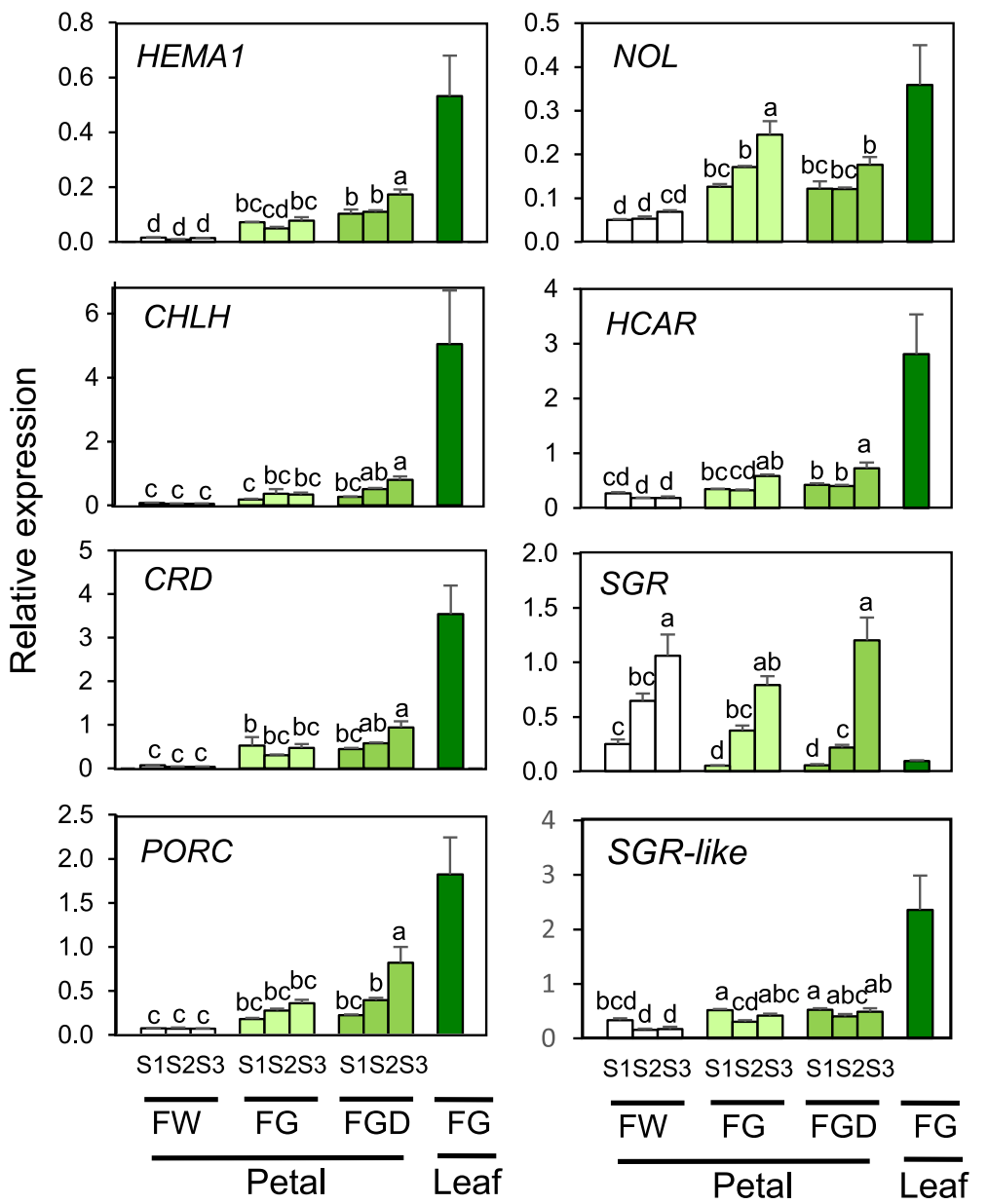

Fig. 5 RT-qPCR analysis of $\mathrm{Chl}$ metabolic genes in FW, FG, and FGD. Mean values ( \pm SD) of three biological replicates are shown. Designations of petal developmental stages and cultivars are as in Fig. 2. Gene abbreviations are as in Fig. 1. The differences among petals (FW, FG, and FGD) were analyzed by Tukey-Kramer multiple-comparison test. Different letters indicate significant differences at $P<0.05$

We identified 11 transcription factor genes expressed significantly higher in FW petals than in FG petals (Table 1, upper part). Five of them encoded MYB domain proteins and showed high fold change values (25.8-60.4). Four of these $M Y B$ sequences were most closely related to MYB113 in the Arabidopsis R2R3-Myb family and were designated MYB113-like. Arabidopsis MYB113 is involved in flavonoid biosynthesis [18, 19]. However, the expression of one of the MYB113-like genes was not associated with that of the flavonoid biosynthesis genes dihydroflavonol 4-reductase, chalcone synthase, anthocyanidin synthase, and chalcone isomerase (Additional file 5 Figure S3). A gene encoding an ovate family protein showed the highest fold change value of 84.8. Expression of 27 transcription factor genes was down-regulated in FW petals, including 4 DREB and EAR motif protein (ERF) genes, 5 homeobox protein 40 (HD40) genes, 5 integrase-type DNA-binding superfamily protein genes, and 3 B-box type zinc finger protein with CCT domain (CONSTANS-like, COL) genes
(Table 1, lower part). The COL gene sequences were most closely related to COL6 or COL16 in Arabidopsis and were designated COL16-like.

We identified 14 transcription factor genes expressed significantly higher in FGD petals than in FG petals (Table 2, upper part). Among them, two genes encoding MYB3 proteins showed the highest fold change values (100.5 and 91.4). Three genes encoding MYB4 also showed high fold change values (19.3-42.8). Ten transcription factor genes were expressed at significantly lower levels in FGD petals than in FG petals (Table 2, lower part). Six of them encoded mini zinc finger 2 proteins and showed extremely low relative expression in FGD petals (fold change values from -68.9 to -179.5$)$.

To validate petal color-specific expression, we performed RT-qPCR analysis of 11 transcription factor genes in S3 petals of white- and green-flowered chrysanthemum cultivars. These genes were selected as representatives of different groups of transcription factors identified by the 

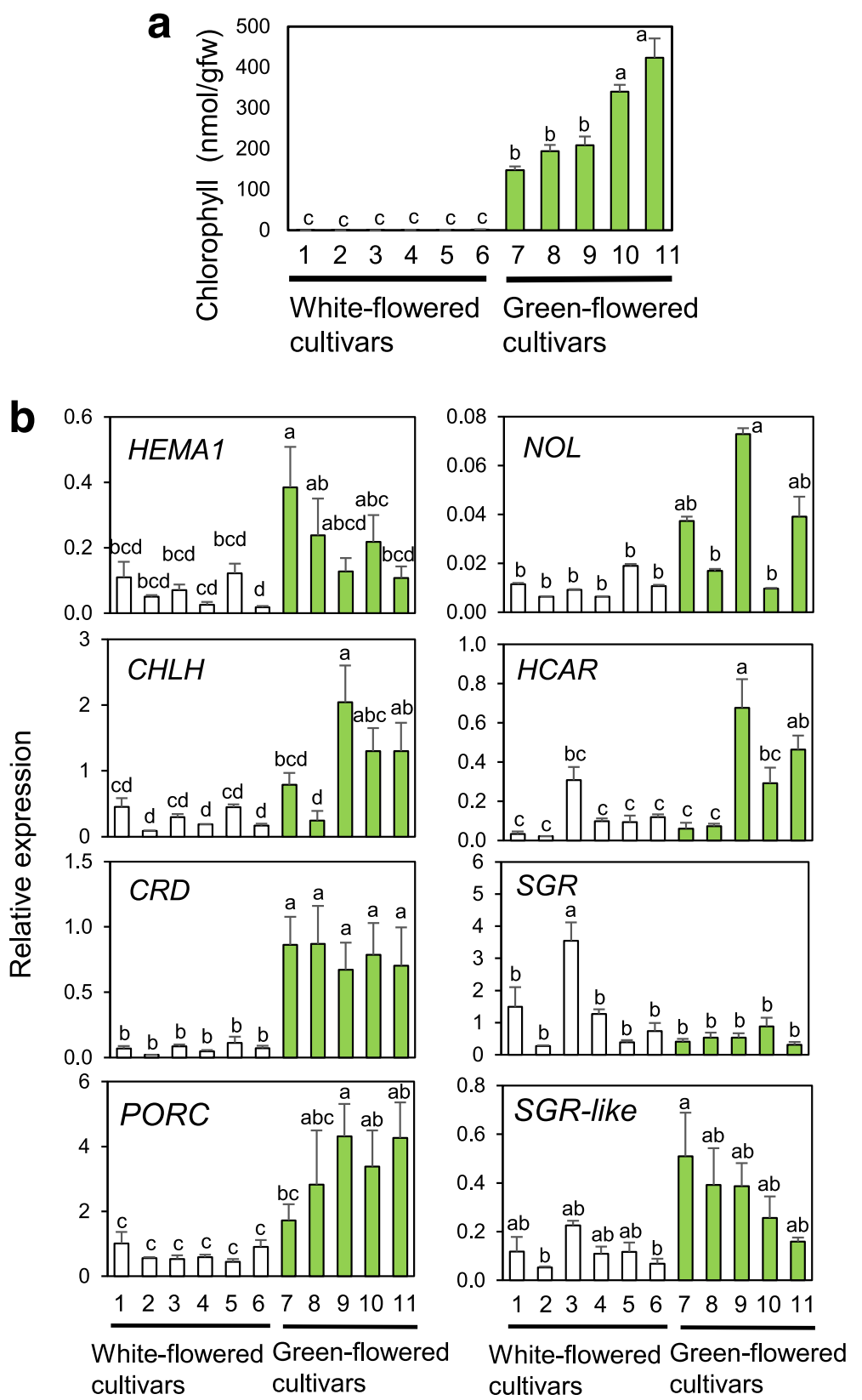

Fig. 6 RT-qPCR analysis of Chl metabolic genes in petals of white- and green-flowered chrysanthemum cultivars. a Chl content; (b) expression of selected genes related to $\mathrm{Chl}$ metabolism. Mean values $( \pm S D)$ of three biological replicates are shown. Different letters indicate significant differences by Tukey-Kramer multiple-comparison test $(P<0.05)$. Gene abbreviations are as in Fig. 1. White-flowered cultivars: 1, Estrella; 2 , Baltica White; 3, Ping Pong Super; 4, Sei Elsa; 5, Radost; 6, Ferry. Green-flowered cultivars: 7, Sei Green Needle; 8, Greea; 9, Anastasia Green; 10, Olive; 11, Green Lizard

microarray analysis (Tables 1 and 2). Among them, the expression of MYB113-like was restricted to white petals (Fig. 7a), although there was a variability in the expression levels among cultivars. In contrast, the expression of ERF and COL16-like tended to be higher or was significantly higher in green petals than in white petals (Fig. 7a). There was no correlation between the transcript levels of the other 8 genes and Chl content (Additional file 6 Figure S4).
We also analyzed the expression of MYB113-like, COL16-like, and ERF during development of FW, FG, and FGD petals, and in FG leaves. The expression of a MYB113-like gene in FW increased as petals matured, whereas it remained low in FG and FGD petals, and was also low in leaves (Fig. 7b). The expression of a COL16-like gene was extremely low in FW petals and high in FG leaves. FGD petals showed 
Table 1 Transcription factors differentialy expressed between FG and FW petals (fold change $>15$ or $>-15$ )

\begin{tabular}{|c|c|c|c|c|c|c|c|}
\hline Probe ID & & $\begin{array}{l}\text { GenBank accession } \\
\text { no }\end{array}$ & Fold Change & P-Value & $\begin{array}{l}\text { Closest Arabid } \\
\text { Classification }\end{array}$ & psis gene & Arabidopsis annotation \\
\hline PD0028_011900 & * & IABW01012977 & 84.8 & 8.E-07 & AT3G52525.1 & OFP & $\begin{array}{l}\text { Arabidopsis thaliana OVATE FAMILY PROTEIN 6, } \\
\text { OFP6 O }\end{array}$ \\
\hline PD0028_044537 & * & IABW01054620 & 60.4 & 9.E-05 & AT1G66370.1 & MYB & myb domain protein 113 \\
\hline PD0028_148815 & & IABW01198808 & 50.1 & 1.E-04 & AT1G66370.1 & MYB & myb domain protein 113 \\
\hline PD0028_075950 & & IABW01104970 & 48.9 & 1.E-05 & AT1G66370.1 & MYB & myb domain protein 113 \\
\hline PD0028_154888 & & IABW01206257 & 32.4 & 3.E-04 & AT2G36026.1 & OFP & Ovate family protein \\
\hline PD0028_150392 & & IABW01200686 & 31.7 & 3.E-05 & AT3G52525.1 & OFP & $\begin{array}{l}\text { ARABIDOPSIS THALIANA OVATE FAMILY PROTEIN 6, } \\
\text { OFP6 O }\end{array}$ \\
\hline PD0028_033761 & & IABW01039606 & 30.7 & 2.E-05 & AT1G59750.1 & ARF & auxin response factor 1 \\
\hline PD0028_044920 & & IABW01055129 & 28.0 & 4.E-04 & AT1G66370.1 & MYB & myb domain protein 113 \\
\hline PD0028_048158 & & IABW01059862 & 25.8 & 1.E-04 & AT1G19510.1 & MYB & RADIALIS-LIKE SANT/MYB 4, RAD-like 5 \\
\hline PD0028_081008 & & IABW01114181 & 25.6 & 2.E-04 & AT1G60700.1 & $\mathrm{FHA}$ & SMAD/FHA domain-containing protein \\
\hline PD0028_103797 & & IABW01145611 & 15.3 & 7.E-03 & AT4G17880.1 & bHLH & $\begin{array}{l}\text { Basic helix-loop-helix (bHLH) DNA-binding } \\
\text { family protein }\end{array}$ \\
\hline PD0028_168726 & & IABW01092014 & -296.7 & 1.E-03 & AT5G06839.3 & bZIP & TGACG (TGA) motif-binding protein 10 \\
\hline PD0028_094749 & & IABW01134810 & -38.8 & $0 . E+00$ & AT5G67190.1 & AP2_ERF & DREB and EAR motif protein 2 \\
\hline PD0028_062703 & & IABW01082439 & -36.4 & $0 . E+00$ & AT5G67190.1 & AP2_ERF & DREB and EAR motif protein 2 \\
\hline PD0028_043748 & & IABW01053524 & -36.0 & $0 . E+00$ & AT5G67190.1 & AP2_ERF & DREB and EAR motif protein 2 \\
\hline PD0028_010170 & & IABW01011053 & -35.0 & $0 . E+00$ & AT1G75250.1 & MYB & RADIALIS-LIKE SANT/MYB 3, RAD-like 6 \\
\hline PD0028_048604 & * & IABW01060484 & -33.6 & $0 . E+00$ & AT5G67190.1 & AP2_ERF & DREB and EAR motif protein 2 \\
\hline PD0028_069119 & & IABW01093153 & -30.6 & 2.E-03 & AT4G36740.1 & $\mathrm{HD}$ & homeobox protein $40, \mathrm{HD} 40$ \\
\hline PD0028_076607 & * & IABW01106213 & -29.3 & 3.E-03 & AT4G36740.1 & $\mathrm{HD}$ & homeobox protein $40, \mathrm{HD} 40$ \\
\hline PD0028_046802 & & IABW01058023 & -28.9 & 2.E-03 & AT4G36740.1 & $\mathrm{HD}$ & homeobox protein $40, \mathrm{HD} 40$ \\
\hline PD0028_093450 & & IABW01133272 & -25.8 & 1.E-03 & AT4G36740.1 & $\mathrm{HD}$ & homeobox protein $40, \mathrm{HD} 40$ \\
\hline PD0028_036988 & & IABW01044039 & -24.4 & 1.E-03 & AT4G36740.1 & $\mathrm{HD}$ & homeobox protein $40, \mathrm{HD} 40$ \\
\hline PD0028_003905 & * & IABW01004158 & -22.6 & $0 . E+00$ & AT1G25440.1 & $\mathrm{CO}$ & $\begin{array}{l}\text { B-box type zinc finger protein with CCT } \\
\text { domain, COL16 }\end{array}$ \\
\hline PD0028_009958 & & IABW01010820 & -20.7 & 1.E-03 & AT1G75410.1 & $\mathrm{HD}$ & BEL1-like homeodomain 3 \\
\hline PD0028_150651 & & IABW01201015 & -18.4 & 2.E-03 & AT5G52020.1 & AP2_ERF & Integrase-type DNA-binding superfamily protein \\
\hline PD0028_029276 & & IABW01034060 & -18.4 & $0 . E+00$ & AT1G68520.1 & $\mathrm{CO}$ & $\begin{array}{l}\text { B-box type zinc finger protein with CCT } \\
\text { domain, COL6 }\end{array}$ \\
\hline PD0028_001574 & & IABW01001664 & -18.3 & 1.E-03 & AT5G14280.1 & GeBP & DNA-binding storekeeper protein-related \\
\hline PD0028_100279 & & IABW01141429 & -18.2 & 1.E-03 & AT3G11580.1 & B3 & AP2/B3-like transcriptional factor family protein \\
\hline PD0028_107134 & & IABW01149631 & -17.7 & $0 . E+00$ & AT5G65050.3 & MADS & MADS AFFECTING FLOWERING 2, AGAMOUS-like 31 \\
\hline PD0028_074156 & & IABW01101743 & -17.6 & 1.E-03 & AT2G43060.1 & bHLH & ILI1 binding bHLH 1 \\
\hline PD0028_082618 & & IABW01117162 & -16.6 & 4.E-03 & AT5G52020.1 & AP2_ERF & Integrase-type DNA-binding superfamily protein \\
\hline PD0028_145445 & & IABW01194763 & -16.1 & $0 . E+00$ & AT5G56860.1 & GATA & GATA, nitrate-inducible, carbon metabolism-involved \\
\hline PD0028_082089 & & IABW01116183 & -15.9 & 3.E-03 & AT5G52020.1 & AP2_ERF & Integrase-type DNA-binding superfamily protein \\
\hline PD0028_098862 & & IABW01139756 & -15.8 & 3.E-03 & AT5G52020.1 & AP2_ERF & Integrase-type DNA-binding superfamily protein \\
\hline PD0028_069340 & & IABW01093503 & -15.8 & 2.E-03 & AT5G52020.1 & AP2_ERF & Integrase-type DNA-binding superfamily protein \\
\hline PD0028_117926 & & IABW01162197 & -15.8 & 5.E-03 & AT1G25440.1 & $\mathrm{CO}$ & $\begin{array}{l}\text { B-box type zinc finger protein with CCT } \\
\text { domain, COL16 }\end{array}$ \\
\hline PD0028_148039 & & IABW01197925 & -15.8 & 1.E-03 & AT3G23250.1 & MYB & myb domain protein 15 \\
\hline PD0028_129536 & & IABW01175867 & -15.4 & 1.E-03 & AT1G32150.1 & bZIP & basic region/leucine zipper transcription factor 68 \\
\hline
\end{tabular}


Table 2 Transcription factors differentialy expressed between FG and FGD petals (fold change $>15$ or $>-15$ )

\begin{tabular}{|c|c|c|c|c|c|c|c|}
\hline Probe ID & & $\begin{array}{l}\text { GenBank } \\
\text { accession no. }\end{array}$ & $\begin{array}{l}\text { Fold } \\
\text { Change }\end{array}$ & $P$-Value & Closest Arabidopsis gene & Classification & Arabidopsis annotation \\
\hline PD0028_006794 & & IABW01007316 & 100.5 & 6.E-04 & AT1G75250.1 & MYB & RADIALIS-LIKE SANT/MYB 3, RAD-like 6 \\
\hline PD0028_092972 & * & IABW01132689 & 91.4 & 9.E-04 & AT1G75250.1 & MYB & RADIALIS-LIKE SANT/MYB 3, RAD-like 6 \\
\hline PD0028_048158 & & IABW01059862 & 42.8 & 2.E-04 & AT1G19510.1 & MYB & RADIALIS-LIKE SANT/MYB 4, RAD-like 5 \\
\hline PD0028_034984 & * & IABW01041136 & 29.7 & 2.E-03 & AT3G17730.1 & NAC & NAC domain containing protein 57 \\
\hline PD0028_033512 & * & IABW01039301 & 25.2 & $6 . \mathrm{E}-03$ & AT2G27300.1 & NAC & $\begin{array}{l}\text { Arabidopsis NAC domain containing protein } \\
40 \text {, NTM1-like 8, NTL8 }\end{array}$ \\
\hline PD0028_007777 & & IABW01008418 & 23.5 & 3.E-02 & AT4G32280.1 & AUX_IAA & indole-3-acetic acid inducible 29 \\
\hline PD0028_190240 & & IABW01206912 & 21.6 & 1.E-05 & AT5G05120.1 & $\mathrm{C} 2 \mathrm{H} 2 \mathrm{ZnF}$ & $\mathrm{C} 2 \mathrm{H} 2$ and $\mathrm{C} 2 \mathrm{HC}$ zinc fingers superfamily protein \\
\hline PD0028_071210 & * & IABW01096525 & 20.4 & 4.E-03 & AT5G25390.2 & AP2_ERF & $\begin{array}{l}\text { shine3, SHN3, Integrase-type DNA-binding } \\
\text { superfamily protein }\end{array}$ \\
\hline PD0028_064158 & & IABW01084746 & 19.8 & $6 . \mathrm{E}-04$ & AT1G19510.1 & MYB & RADIALIS-LIKE SANT/MYB 4, RAD-like 5 \\
\hline PD0028_102746 & * & IABW01144347 & 19.3 & 5.E-04 & AT1G19510.1 & MYB & RADIALIS-LIKE SANT/MYB 4, RAD-like 5 \\
\hline PD0028_113111 & & IABW01156549 & 18.4 & 3.E-03 & AT5G42630.1 & GARP & KANADI 4, ABERRANT TESTA SHAPE \\
\hline PD0028_037235 & & IABW01044426 & 18.0 & 4.E-03 & AT5G25390.2 & AP2_ERF & $\begin{array}{l}\text { shine3, SHN3, Integrase-type DNA-binding } \\
\text { superfamily protein }\end{array}$ \\
\hline PD0028_081008 & & IABW01114181 & 17.9 & 4.E-04 & AT1G60700.1 & FHA & SMAD/FHA domain-containing protein \\
\hline PD0028_142351 & & IABW01190973 & 15.0 & 3.E-04 & AT3G62240.1 & $\mathrm{C} 2 \mathrm{H} 2 \mathrm{ZnF}$ & RING/U-box superfamily protein \\
\hline PD0028_132595 & & IABW01179425 & -179.5 & 2.E-05 & AT3G28917.1 & $\mathrm{ZF}_{-} \mathrm{HD}$ & mini zinc finger 2 , MIF2 \\
\hline PD0028_125957 & & IABW01171648 & -142.3 & 2.E-05 & AT3G28917.1 & $\mathrm{ZF}_{-} \mathrm{HD}$ & mini zinc finger 2, MIF2 \\
\hline PD0028_105609 & & IABW01147785 & -138.9 & 4.E-05 & AT3G28917.1 & $\mathrm{ZF}_{-} \mathrm{HD}$ & mini zinc finger 2 , MIF2 \\
\hline PD0028_043321 & & IABW01052932 & -122.2 & 4.E-05 & AT3G28917.1 & $\mathrm{ZF} \_\mathrm{HD}$ & mini zinc finger 2, MIF2 \\
\hline PD0028_064889 & & IABW01085974 & -96.2 & 2.E-05 & AT3G28917.1 & $\mathrm{ZF}_{-} \mathrm{HD}$ & mini zinc finger 2 , MIF2 \\
\hline PD0028_041425 & * & IABW01050224 & -68.9 & 6.E-05 & AT3G28917.1 & $\mathrm{ZF} \_\mathrm{HD}$ & mini zinc finger 2, MIF2 \\
\hline PD0028_076231 & & IABW01105570 & -20.0 & 7.E-03 & AT2G37060.1 & CCAAT & $\begin{array}{l}\text { nuclear factor } Y \text {, subunit } B 8 \text {, nuclear factor } Y \text {, } \\
\text { subunit } \\
\text { B8 }\end{array}$ \\
\hline PD0028_086808 & & IABW01124961 & -18.9 & 3.E-03 & AT5G51990.1 & AP2_ERF & $\begin{array}{l}\text { DEHYDRATION-RESPONSIVE ELEMENT-BINDING } \\
\text { PROTEIN } 1 D\end{array}$ \\
\hline PD0028_042367 & & IABW01051507 & -17.9 & 2.E-03 & AT4G34410.1 & AP2_ERF & redox responsive transcription factor 1 \\
\hline PD0028_148039 & & IABW01197925 & -15.6 & 3.E-04 & AT3G23250.1 & MYB & myb domain protein 15 \\
\hline
\end{tabular}

* Genes whose expression levels in the white and green petals were analyzed by RT-qPCR (Figs.6, 7, and S3)

higher COL16-like gene expression than did FW and FG petals, and the expression increased as FG and FGD petals matured. The expression of an ERF gene was highest in FG and FGD petals and increased as petals matured.

We also examined the expression profiles of transcription factors previously identified as negative or positive regulators of Chl biosynthesis. GLK, HY5, and GNC enhance Chl biosynthesis [7-9]. ESTs encoding these transcription factors showed different expression patterns: GNC and HY5 expression in petals was positively and negatively correlated with Chl content, respectively. There was no marked difference in the expression level of GLK in petals of FW, FG and FGD. PIF1 and PIF3, have been shown to negatively regulate Chl biosynthesis [10]. However, in our microarray analysis, PIF1 and PIF3 expression levels were positively associated with Chl content in FW, FG, and FGD petals (Additional file 7 Figure S5). The results suggest that these transcription factors are not involved in the regulation of $\mathrm{Chl}$ accumulation in petals and that different transcription factors control Chl accumulation in leaves and petals.

\section{Comparison of plastid ultrastructure in $\mathrm{FW}, \mathrm{FG}$, and FGD petals}

We compared plastid ultrastructure among FW, FG, and FGD petals at different developmental stages and FG leaves by using TEM. At S1, epidermal cells of all petals contained electron-dense small plastids (Fig. 8a). Mesophyll cells of all petals also contained small plastids with lower electron density (Fig. 8b). At S2, the development of membrane structures was evident in the plastids of mesophyll cells of FG and FGD petals, whereas those 
a
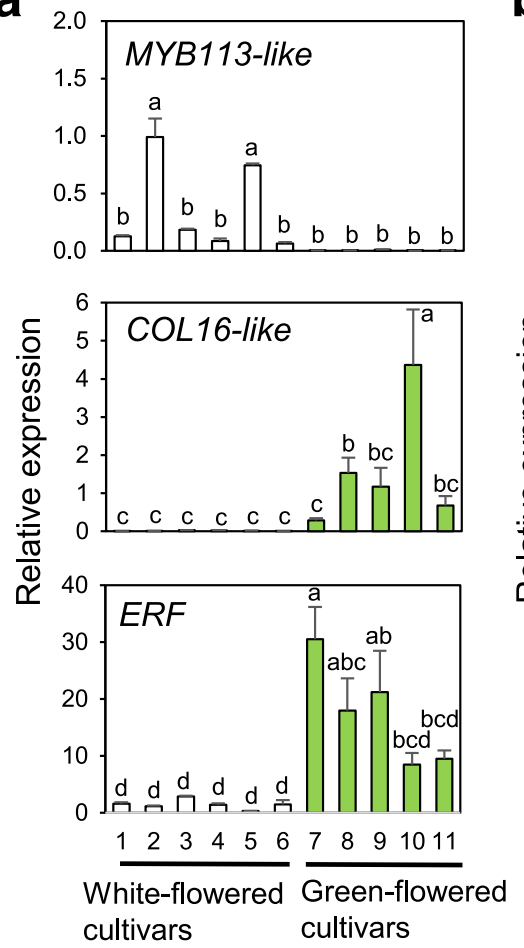

b
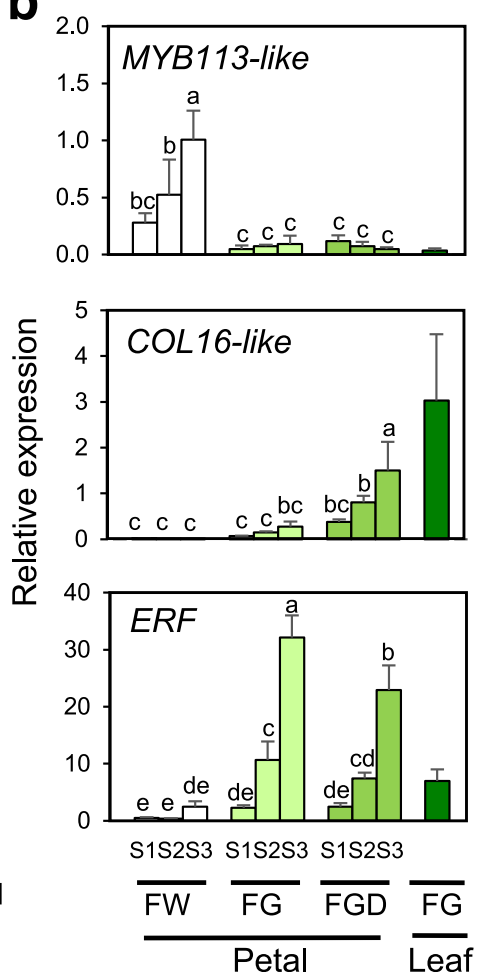

Fig. 7 RT-GPCR analysis of transcription factor genes differentially expressed in petals of white- and green-flowered chrysanthemum cultivars. Mean values $( \pm$ SD) of three biological replicates are shown. Different letters indicate significant differences by Tukey-Kramer multiple-comparison test $(P<0.05)$. Designations of petal developmental stages and cultivars are as in Figs. 2 and 6

of FW cells contained plastids with destroyed thylakoid membranes (Fig. 8b). At S3, we observed plastid debris in both epidermal and mesophyll cells of FW petals (Fig. 8a and b; Additional file 8 Figure S6). In contrast, S3 FG and FGD petals still contained plastids with a welldeveloped thylakoid system. In leaves, plastids were larger than those in FG and FGD petals at S3 and contained large starch granules (Fig. 8c). Plastids were found only in mesophyll but not in epidermal cells (Additional file 8 Figure S6).

\section{Discussion}

To clarify the key factors that determine different levels of $\mathrm{Chl}$ accumulation in leaves and petals of chrysanthemums, we performed microarray analysis and searched for the differences in the expression levels of genes. GO classification showed that, among the downregulated genes in FW petals, genes associated with "plastids", "chloroplasts", and "electron transport or energy pathways" were highly represented. These results indicate that many of the genes related to photosynthesis whose products function in the chloroplast were transcriptionally inactive in FW petals. TEM observation of petals supports the hypothesis: at the late stage of development, green petals contain chloroplasts with well-developed thylakoid membranes, whereas white petals have lost chloroplasts. TEM observation also showed that, in green petals, both mesophyll and epidermal cells contain plastids, whereas only mesophyll cells contain plastids in leaves. The result indicates that leaves and petals have different patterns of Chl accumulation: Chls are present only in mesophyll cells in leaves, whereas they are present in both epidermal and mesophyll cells in green petals. Therefore, it is reasonable to assume that the regulatory mechanisms for $\mathrm{Chl}$ accumulation differ in leaves and petals.

Microarray analysis showed that the expression of many Chl biosynthesis genes was lower in white petals than in green petals. In particular, the expression of genes encoding CHLH, CRD, HEMA1, and PORC was well associated with Chl content in petals and leaves of the FW, FG, and FGD cultivars. It is worth noting that the expression of the genes encoding these enzymes is induced by light and they are considered as key enzymes for Chl biosynthesis during photomorphogenesis [20-22]. We propose that Chl biosynthesis activity is lower in white petals than in leaves and green petals because of the remarkably low levels of expression of these genes.

There was no association between the expression levels of most Chl catabolic genes and Chl content in the petals of FW, FG, and FGD. However, SGR 


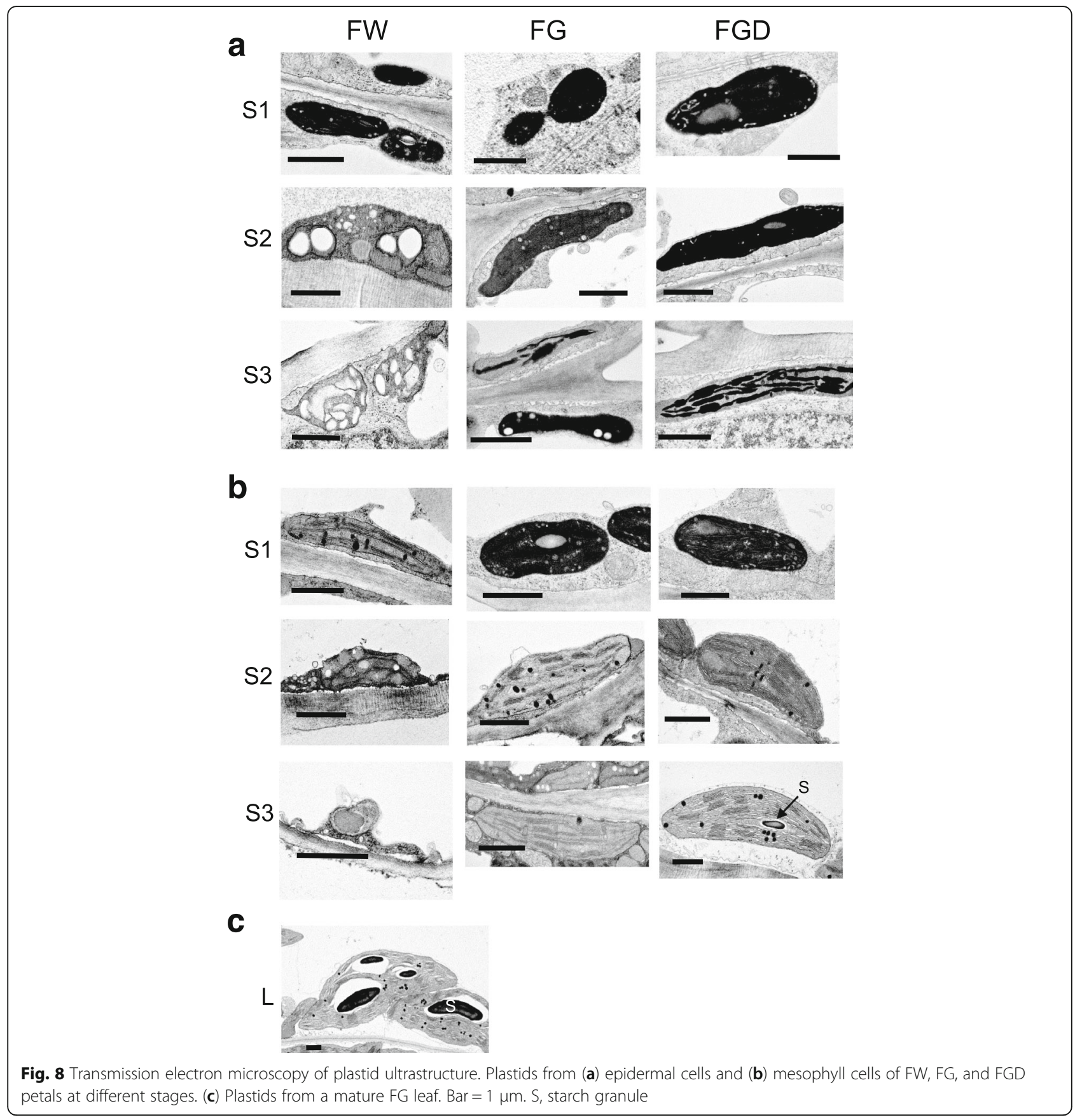

expression in mature petals of these cultivars was markedly higher than that in leaves. SGR is responsible for stay-green phenotypes of leaves in rice and Arabidopsis $[23,24]$ and also non-photosynthetic tissues such as fruits of tomato, pepper, and kiwi, in which Chl degradation normally occurs at the onset of fruit ripening $[25,26]$. Several lines of evidence indicate that SGR plays a key role in the initiation of Chl degradation by destabilizing protein-pigment complexes in the thylakoid membranes [27, 28]. Very recently, Shimoda et al. [29] revealed that SGR is a Mg-dechelatase, which catalyzes the conversion of
Chl $a$ to pheophytin $a$, which is the first step of Chl degradation. We then assume that SGR maintains high Chl catabolic activity and contributes to the absence or low level of Chls in chrysanthemum petals. Our results on the expression patterns of Chl metabolic genes in chrysanthemums are similar to our previous results on carnation and Arabidopsis [6].

Based on our results, we hypothesize that a low rate of Chl biosynthesis and a high rate of Chl degradation lead to the absence of Chls in white chrysanthemum petals. We assumed that factors that suppress 
Chl biosynthesis may exist in non-green petals. Higher rate of $\mathrm{Chl}$ biosynthesis in green petals may result from a loss or reduced activity of the suppressors. We then searched for transcription factors whose expression is related to Chl content and identified COL16-like, ERF, and MYB113-like, which were coordinately expressed with Chl content in petals.

The white petal-specific MYB113-like genes belong to the R2R3-MYB family, which controls plant-specific physiological processes including primary and secondary metabolism, cell fate and identity, development, and responses to biotic and abiotic stresses [30]. Arabidopsis MYB113 belongs to subclass 6, which is involved in flavonoid biosynthesis $[18,19]$, but the expression level of the chrysanthemum MYB113-like gene in petals was not associated with those of flavonoid biosynthesis genes (Additional file 5 Figure S3). We showed that a COL16like gene was highly expressed in green petals and leaves of chrysanthemum. In Arabidopsis and Medicago truncatula, the COL protein family is divided into Groups I to III on the basis of conserved domains [31]. Group I might regulate flowering time [32-34]. The EST sequence of chrysanthemum COL16-like was most similar to Arabidopsis AtCOL16 (AT1G25440) of Group II, for which limited information about their physiological function is available [35]. Another green petal-specific transcription factor, ERF, belongs to the APETALA2 (AP2) family. ERFs control growth and development as well as responses to environmental stimuli [36, 37]. Several ERFs regulate primary and secondary metabolism. For example, Catharanthus roseus ERFs (ORCA2 and ORCA3) enhance the jasmonate-responsive expression of strictosidine synthase, which is required for terpenoid indole alkaloid synthesis [38]. To our knowledge, the involvement of COL16 and ERF in Chl metabolism has never been reported.

\section{Conclusion}

From our transcriptome analysis, we suggest that the low expression levels of chlorophyll biosynthesis genes and the high expression levels of a chlorophyll catabolic gene lead to the absence of chlorophylls in white chrysanthemum petals. We hypothesize that factor(s) that suppress(es) chlorophyll biosynthesis gene expression may exist in white petals. Higher rate of chlorophyll biosynthesis in green petals may result from the loss of such suppressors. We identified candidate transcriptional regulators that may be involved in chlorophyll metabolism and/or accumulation in petals. To provide further insight into the regulatory mechanism of tissue-specific chlorophyll accumulation, the function of the candidate transcription factors should be evaluated.

\section{Additional files} Additional file 1: Table S1. Primers used for RT-qPCR analysis.
(PPTX $67 \mathrm{~kb}$ )

Additional file 2: Figure S1. Chlorophyll content in FW, FG, and FGD leaves. Mean values $( \pm S D$ ) of three biological replicates are shown. (PPTX $45 \mathrm{~kb}$ )

Additional file 3: Table S2. List of chlorophyll metabolic genes. (PPTX 69 kb)

Additional file 4: Figure S2. Photographs of flowers of white- and green-flowered chrysanthemum cultivars used for RT-qPCR analysis presented in Figs. 6 and 7, and Additional file 5 Figure S4. (PPTX $1046 \mathrm{~kb}$ )

Additional file 5: Figure S3. Expression of MYB113-like and anthocyanin biosynthesis genes in FW, FG, and FGD. Microarray data were obtained as described in Fig. 4. ANS, anthocyanidin synthase; CHI, chalcone isomerase; CHS, chalcone synthase; DFR, dihydroflavonol 4-reductase. GenBank accession number of each gene is indicated in parentheses. (PPTX $50 \mathrm{~kb}$ )

Additional file 6: Figure S4. RT-qPCR analysis of selected transcription factor genes in petals of white- and green-flowered chrysanthemum cultivars. Cultivar numbers are as in Additional file 4 Figure S2. A total of 11 genes were selected by microarray analysis (Tables 1 and 2). Three of them were differentially expressed between white and green petals

(Fig. 7). The expression levels of the remaining 8 genes (presented in this Figure S4.), were not significantly different between white and green petals. Different letters indicate significant differences in Tukey-Kramer multiple-comparison test $(P<0.05)$. (PPTX $108 \mathrm{~kb}$ )

Additional file 7: Figure S5. Expression of Chl-related transcription factor genes in FW, FG, and FGD. Microarray data were obtained as described in Fig. 4. The GenBank accession number of each gene is indicated in parentheses. (PPTX $49 \mathrm{~kb}$ )

Additional file 8: Figure S6. Transmission electron microscopy at low magnification. Transverse sections of petals at stages 1 to 3 (S1 to S3), and leaves $(\mathrm{L})$. The uppermost cell layer in each photograph is the epidermal cell layer. Bar $=20 \mu \mathrm{m}$. (PPTX $10712 \mathrm{~kb}$ )

\section{Abbreviations}

CGA1: Cytokinin responsive gata factor1; Chl: Chlorophyll; CHLG: Chl synthase; CHLH: Mg-protoporphyrin IX chelatase (Mg-chelatase) H subunit; CHLI: Mg-chelatase I subunit; CHLM: Mg-protoporphyrin IX methyltransferase; COL: CONSTANS-like; CRD: Mg-protoporphyrin IX monomethylester cyclase; DVR: Divinyl chlorophyllide a 8-vinyl-reductase; ERF: DREB and EAR motif protein; EST: Expressed sequence tag; GLK: GOLDEN2-LIKE; GNC: Gata, nitrate-inducible, carbon-metabolism involved; GNL: GNC-LIKE; GO: Gene ontology; HCAR: Hydroxymethyl Chl a reductase; HEMA: Glutamyl-tRNA reductase; HEMB: 5-aminolevulinate dehydratase; HEMD: Uroporphyrinogen III synthase; HEMG: Protoporphyrinogen III oxidase; HY5: Long hypocotyl5; NOL: Non-yellow coloring one-like; PaO: Pheophorbide a oxygenase; PIF: Phytochrome-interacting factor; PORC: Protochlorophyllide oxidoreductase C; PPH: Pheophytinase; RCCR: Red Chl catabolite reductase; RT-qPCR: Quantitative real-time PCR; SGR: Stay-green; TEM: Transmission electron microscopy

\section{Acknowledgements}

Not applicable.

\section{Funding}

This work was supported in part by a Grant-in-Aid from the National Agriculture and Food Research Organization (NARO) to A.O. and K. Sasaki., JSPS KAKENHI Grant Number 25292025 to A.O., and JSPS Research Fellowships for Young Scientists to C.O-Y.

\section{Availability of data and materials}

All data supporting the findings of this study are contained within the published article and supplementary information files. Microarray data used in the study are registered in National Center for Biotechnology Information 
Gene Expression Omnibus (http://www.ncbi.nlm.nih.gov/geo/) under accession number GSE102752.

\section{Open access}

This article is distributed under the terms of the Creative Commons Attribution 4.0 International License (http://creativecommons.org/licenses/by/ 4.0/), which permits unrestricted use, distribution, and reproduction in any medium, provided you give appropriate credit to the original author(s) and the source, provide a link to the Creative Commons license, and indicate if changes were made. The Creative Commons Public Domain Dedication waiver (http://creativecommons.org/publicdomain/zero/1.0/) applies to the data made available in this article, unless otherwise stated.

\section{Authors' contributions}

A.O. conceived the project, performed RT-qPCR analysis, and wrote the article. K. Sasaki performed microarray analysis. K.N. performed GO analysis. C.O.-Y. and M.H. conducted HPLC analysis. K. Sumitomo contributed to the experimental design. All authors read and approved the final manuscript.

\section{Ethics approval and consent to participate}

Not applicable.

\section{Consent for publication}

Not applicable.

\section{Competing interests}

The authors declare that they have no competing interests.

\section{Publisher's Note}

Springer Nature remains neutral with regard to jurisdictional claims in published maps and institutional affiliations.

\section{Author details}

${ }^{1}$ Institute of Vegetable and Floriculture Science, National Agriculture and Food Research Organization, Fujimoto 2-1, Tsukuba, Ibaraki 305-0852, Japan. ${ }^{2}$ Institute of Fruit Tree and Tea Science, National Agriculture and Food Research Organization, Fujimoto 2-1, Tsukuba, Ibaraki 305-8605, Japan. ${ }^{3}$ College of Bioresource Sciences, Nihon University, 1866 Kameino, Fujisawa, Kanagawa 252-0880, Japan.

Received: 18 August 2017 Accepted: 8 November 2017

Published online: 15 November 2017

\section{References}

1. Niyogi K. Safety valves for photosynthesis. Curr Opin Plant Biol. 2000;3:455-60.

2. Pyke KA, Page AM. Plastid ontogeny during petal development in Arabidopsis. Plant Physiol. 1998;116:797-803.

3. Tanaka A, Tanaka R. Chlorophyll metabolism. Curr Opin Plant Biol. 2006: 9:248-55.

4. Masuda T, Fujita Y. Regulation and evolution of chlorophyll metabolism. Photochem Photobiol Sci. 2008;7:1131-49.

5. Hörtensteiner S. Update on the biochemistry of chlorophyll breakdown. Plant Mol Biol. 2013;82:505-17.

6. Ohmiya A, Hirashima M, Yagi M, Tanase K, Yamamizo C. Identification of genes associated with chlorophyll accumulation in flower petals. PLoS One. 2014;9:e113738.

7. Lee J, He K, Stolc V, Lee H, Figueroa P, Gao Y, Tongprasit W, Zhao H, Lee I, Denga $\mathrm{XW}$. Analysis of transcription factor HY5 genomic binding sites revealed its hierarchical role in light regulation of development. Plant Cell. 2007:19:731-49.

8. Waters MT, Wang P, Korkaric M, Capper RG, Saunders NJ, Langdale JA. GLK transcription factors coordinate expression of the photosynthetic apparatus in Arabidopsis. Plant Cell. 2009;21:1109-28.

9. Mara CD, Irish VF. Two GATA transcription factors are downstream effectors of floral homeotic gene action in Arabidopsis. Plant Physiol. 2008;147:707-18.

10. Huq E, Al-Sady B, Hudson M, Kim C, Apel K, Quail P. Phytochrome-interacting factor 1 is a critical bHLH regulator of chlorophyll biosynthesis. Science. 2004; 305:1937-41.

11. Qiu K, Li Z, Yang Z, Chen J, Wu S, Zhu X, Gao S, Gao J, Ren G, Kuai B, Zhou $X$. EIN3 and ORE1 accelerate degreening during ethylene-mediated leaf senescence by directly activating chlorophyll catabolic genes in Arabidopsis. PLoS Genet. 2015;11:e1005399.
12. Oda-Yamamizo C, Mitsuda N, Sakamoto S, Ogawa D, Ohme-Takagi M, Ohmiya A. The NAC transcription factor ANAC046 is a positive regulator of chlorophyll degradation and senescence in Arabidopsis leaves. Sci Rep. 2016;6:23609.

13. Sasaki K, Mitsuda N, Nashima K, Kishimoto K, Katayose Y, Kanamori H, Ohmiya A. Generation of expressed sequence tags for discovery of genes responsible for floral traits of Chrysanthemum morifolium by next-generation sequencing technology. BMC Genomics. 2017; in press

14. Ohba T, Suzuki K, Oura T, Ando T, Noda H, Sakura N, Suzuki H, Shibata D, Asada K, Kato IARTRA. A new database of the Arabidopsis transcriptome and gene-specific sequences for microarray probes and RNAi triggers plant. Biotech. 2009;26:161-5.

15. Nashima K, Shimizu T, Nishitani C, Yamamoto T, Takahashi H, Nakazono M, Itai A, Isuzugawa K, Hanada T, Takashina T, Matsumoto S, Otagaki S, Oikawa A, Shiratake K. Microarray analysis of gene expression patterns during fruit development in European pear (Pyrus communis). Sci Hort. 2013;164:466-73.

16. Ohmiya A, Tanase K, Hirashima M, Yamamizo C, Yagi M. Analysis of carotenogenic gene expression in petals and leaves of carnation (Dianthus caryophyllus L). Plant Breed. 2013;132:423-9.

17. Zapata M, Rodríguez F, Garrido JL. Separation of chlorophylls and carotenoids from marine phytoplankton: a new HPLC method using a reversed phase $\mathrm{C} 8$ column and pyridine-containing mobile phases. Mar Ecol Prog Ser. 2000;195:29-45.

18. Gonzalez A, Zhao M, Leavitt JM, Lloyd AM. Regulation of the anthocyanin biosynthetic pathway by the TTG1/bHLH/Myb transcriptional complex in Arabidopsis seedlings. Plant J. 2008;53:814-27.

19. Dubos C, Stracke R, Grotewold E, Weisshaar B, Martin C, Lepiniec LMYB. Transcription factors in Arabidopsis. Trends Plant Sci. 2010;15:573-81.

20. McCormac AC, Terry MJ. Light signalling pathways leading to the coordinated expression of HEMA1 and Lhcb during chloroplast development in Arabidopsis thaliana. Plant J. 2002;32:549-59.

21. Ma L, Sun N, Liu X, Jiao Y, Zhao H, Deng XW. Organ-specific expression of Arabidopsis genome during development. Plant Physiol. 2005;138:80-91.

22. Stephenson PG, Terry MJ. Light signalling pathways regulating the mgchelatase branchpoint of chlorophyll synthesis during de-etiolation in Arabidopsis thaliana. Photochem Photobiol Sci. 2008;7:1243-52.

23. Kusaba M, Ito H, Morita R, lida S, Sato Y, Fujimoto M, Kawasaki S, Tanaka R, Hirochika H, Nishimura M, Tanaka A. Rice NON-YELLOW COLORING1 is involved in light-harvesting complex $\mid$ and grana degradation during leaf senescence. Plant Cell. 2007;19:1362-75.

24. Ren G, An K, Liao Y, Zhou X, Cao Y, Zhao H, Ge X, Kuai B. Identification of a novel chloroplast protein AtNYE1 regulating chlorophyll degradation during leaf senescence in Arabidopsis. Plant Physiol. 2007;144:1429-41.

25. Barry CS, McQuinn RP, Chung MY, Besuden A, Giovannoni JJ. Amino acid substitutions in homologs of the STAY-GREEN protein are responsible for the green-flesh and chlorophyll retainer mutations of tomato and pepper. Plant Physiol. 2008;147:179-87.

26. Pilkington SM, Montefiori M, Jameson PE, Allan AC. The control of chlorophyll levels in maturing kiwifruit. Planta. 2012;236:1615-28.

27. Hörtensteiner S. Stay-green regulates chlorophyll and chlorophyll-binding protein degradation during senescence. Trends Plant Sci. 2009:14:155-62.

28. Sakuraba Y, Schelbert S, Park SY, Han SH, Lee BD, Andrès CB, Kessler F, Hörtensteiner S, Paek NC. STAY-GREEN and chlorophyll catabolic enzymes interact at light-harvesting complex II for chlorophyll detoxification during leaf senescence in Arabidopsis. Plant Cell. 2012;24:507-18.

29. Shimoda Y, Ito H, Tanaka A. Arabidopsis STAY-GREEN, Mendel's green cotyledon gene, encodes magnesium-dechelatase. Plant Cell. 2016;28:2147-60.

30. Stracke $R$, Werber M, Weisshaar B. The R2R3-MYB gene family in Arabidopsis thaliana. Curr Opin Plant Biol. 2001:4:447-56.

31. Wong ACS, Hecht VFG, Picard K, Diwadkar P, Laurie RE, Wen J, Mysore K, Macknight RC, Weller JL. Isolation and functional analysis of CONSTANS-LIKE genes suggests that a central role for CONSTANS in flowering time control is not evolutionarily conserved in Medicago truncatula. Front Plant Sci. 2014;5:1-10. https://doi.org/10.3389/fpls. 2014.00486

32. Martin J, Storgaard M, Andersen $\mathrm{CH}$, Nielsen KK. Photoperiodic regulation of flowering in perennial ryegrass involving a CONSTANS-like homolog. Plant Mol Biol. 2004:56:159-69.

33. Zhang JX, Wu KL, Tian LN, Zeng SJ, Duan J. Cloning and characterization of a novel CONSTANS-like gene from Phalaenopsis hybrida. Acta Physiol Plant. 2011:33:409-17. 
34. Campoli C, Drosse B, Searle I, Coupland G, von Korff M. Functional characterization of $\mathrm{HvCO}$, the barley (Hordeum vulgare) flowering time ortholog of CONSTANS. Plant J. 2012;69:868-80.

35. Griffiths S, Dunford RP, Coupland G, Laurie DA. The evolution of CONSTANS-Like gene families in barley, rice, and Arabidopsis. Plant Physiol. 2003;131:1855-67.

36. Kazan K. Negative regulation of defense and stress genes by EAR-motifcontaining repressors. Trends Plant Sci. 2006;11:109-12.

37. Licausi F, Ohme-Takagi M, Perata P. APETALA2/ethylene responsive factor (AP2/ERF) transcription factors: mediators of stress responses and developmental programs. New Phytol. 2013;199:639-49.

38. Van Der Fits L, Memelink J. The jasmonate-inducible AP2/ERF domain transcription factor ORCA3 activates gene expression via interaction with a jasmonate-responsive promoter element. Plant J. 2001;25:43-53.

Submit your next manuscript to BioMed Central and we will help you at every step:

- We accept pre-submission inquiries

- Our selector tool helps you to find the most relevant journal

- We provide round the clock customer support

- Convenient online submission

- Thorough peer review

- Inclusion in PubMed and all major indexing services

- Maximum visibility for your research

Submit your manuscript at www.biomedcentral.com/submit
Biomed Central 